\title{
Da institucionalização total à medicalização: relatos sobre os dispositivos de saúde mental em Feira de Santana - BA
}

\author{
From total institutionalization to medicalization: reports from \\ mental health services in Feira de Santana, Bahia
}

\author{
Stefanie de Almeida Macêdo', Willima Cintia Santos Barboza', Yonetane Freitas Tsukuda ${ }^{3}$ \\ 'Autora para correspondência. Departamento de Ciências Humanas e Filosofia, Curso de Psicologia, Universidade Estadual de Feira de Santana. \\ Feira de Santana, Bahia, Brasil. ORCID: 0000-0002-6255-2957. stefanieamacedo@gmail.com \\ ${ }^{2}$ Departamento de Ciências Humanas e Filosofia, Curso de Psicologia, Universidade Estadual de Feira de Santana. Feira de Santana, Bahia, Brasil. \\ ORCID: 0000-0001-6763-5244.willima_cintia@hotmail.com \\ ${ }^{3}$ Departamento de Ciências Humanas e Filosofia, Curso de Psicologia, Universidade Estadual de Feira de Santana. Feira de Santana, Bahia, Brasil. \\ ORCID: 0000-0002-8045-500X. tsukuda.yonetane@gmail.com
}

\begin{abstract}
RESUMO | Este artigo tem por objetivo construir um breve histórico do cuidado em saúde mental, dos primórdios da institucionalização total aos processos de medicalização contemporâneos, tendo como pano de fundo as experiências de estágio de Psicologia vivenciadas no Hospital Especializado Lopes Rodrigues (HELR) e demais dispositivos de saúde mental da cidade de Feira de Santana, Bahia. As reflexões tecidas por Michel Foucault, Franco Basaglia, Erving Goffman e Paulo Amarante, contrapostas e comparadas à vivência do estágio, apontaram para a transição do processo de institucionalização total para o de medicalização da vida. Por meio desta investigação foi possível constatar a permanência de discursos e práticas que não se coadunam com a legislação vigente, a qual propõe um complexo processo de desinstitucionalização em saúde mental, bem como contatar o papel do psicólogo na manutenção deste estado de coisas.
\end{abstract}

PALAVRAS-CHAVE: Desinstitucionalização. Institucionalização total. Medicalização. Saúde mental.

\begin{abstract}
This article aims to build a brief history of mental health care, from the beginnings of total institutionalization to contemporary medicalization processes, taking into account the experiences of the Psychology internship at the Hospital Especializado Lopes Rodrigues (HELR) and other health devices of the city of Feira de Santana, Bahia. The reflections designed by Michel Foucault, Franco Basaglia, Erving Goffman and Paulo Amarante, compared with the experience of the internship, pointed to the transition from the process of total institutionalization to the medicalization of life. Through this investigation it was possible to verify the permanence of discourses and practices that are not in accordance with current legislation, which proposes a complex process of deinstitutionalization in mental health, as well as to contact the psychologist's role in maintaining this state of affairs.
\end{abstract}

KEYWORDS: Deinstitutionalization. Total institutionalization. Medicalization. Mental health. 
Estar internado no hospício não significa nada. São poucos os loucos. A maioria compõe a parte dúbia, verdadeiros doentes mentais. Lutam contra o que se chama doença, quando justamente esta luta é que os define: sem lado, entre o mundo dos chamados normais e a liberdade dos outros. Maura Lopes Cançado

\section{Introdução}

Século XVIII: loucura como doença mental, passível de internação. Século XXI: loucura como transtorno mental, passível de medicalização. Quatro séculos separam uma mudança que não se reflete no cotidiano do cuidado em saúde mental e a manutenção de uma perspectiva persistente: o desvio social deve ser submetido à necessidade de tratamento e recondução à ordem da "normalidade", na qual as definições de doença e transtorno se confundem no pano de fundo da naturalização organicista do indivíduo. Se outrora o recurso utilizado era a institucionalização por meio do internamento permanente nos manicômios, hoje a institucionalização se faz por meio da medicalização dos sujeitos em serviços substitutivos - ou seja, uma nova forma de institucionalização. Derrubados alguns muros físicos, permanecem os estigmas, as insuficiências do tecido social e $\circ$ poder de intervenção da medicina enquanto instituição.

Este cenário pode ser exemplificado pela Rede de Atenção Psicossocial (RAPS) de Feira de Santana Bahia. A RAPS feirense é composta pelo Hospital Especializado Lopes Rodrigues (HELR) - um dos três hospitais psiquiátricos remanescentes do estado -, bem como pelos cinco Centros de Atenção Psicossocial (CAPS) e pelas onze residências terapêuticas. Os cinco CAPS, distribuídos entre CAPSad, CAPSi, CAPS II e III, atendem mais de vinte e sete mil pessoas no município e contam com o apoio de dezesseis psicólogos em sua rede (Mais de 27..., 2018; Cunha, 20181).

Ao longo de um ano de estágio supervisionado do curso de Psicologia da Universidade Estadual de
Feira de Santana (UEFS), nos debruçamos sobre o cuidado em saúde mental oferecido pelo serviço público feirense, contando com experiências de reconhecimento da rede assistencial e de atendimentos psicológicos individuais. Tendo o HELR, os CAPS e as residências terapêuticas como lócus de atuação e reflexão, buscamos demonstrar brevemente neste relato de experiência o percurso epistemológico da transição operada na concepção da doença mental em relação às instituições e as lacunas dessa mudança na prática, que acabam por configurar o cenário institucional-medicalizante. Para tal, apresentamos, numa revisão bibliográfica orientada por Marconi e Lakatos (2006): a institucionalização descrita por Michel Foucault na Grande Internação; a totalização das instituições na perspectiva de Erving Goffman; a tentativa de revisão desse cenário nas reformas psiquiátricas e, por fim, a recaída na medicalização da sociedade.

\section{O grande internamento}

Até o final da ldade Média, a prática de internamento dos sujeitos desviantes estava restrita aos indivíduos acometidos pela lepra. Inúmeros leprosários se instalaram pela Europa. Contudo, com a diminuição da epidemia, os espaços de isolamento perderam sua utilidade, abrindo as portas para a criação de novas formas de exclusão. Primeiramente, substituída pelas doenças venéreas; muito tempo depois, quando estas doenças se tornaram especialidades médicas, as práticas de exclusão ganharam outras formas, como a loucura. Iniciou-se assim o período da "Grande Internação", narrada por Foucault em seu História da Loucura (1972), no qual a loucura foi reduzida ao silêncio e à invisibilidade:

é sob a influência do modo de internamento, tal como ele se constituiu no século XVII, que a doença venérea se isolou, numa certa medida, de seu contexto médico e se integrou, ao lado da loucura, num espaço moral de exclusão. De fato, a verdadeira herança da lepra não é aí que deve ser buscada, mas sim num fenômeno bastante complexo, do qual a medicina demorará para se apropriar. Esse fenômeno é a loucura (Foucault, 1972, p. 8).

1 Entrevista da coordenadora da Rede de Atenção Psicossocial de Feira de Santana, Robervânia Cunha, concedida em 17 de julho de 2018. 
Na tentativa de manter a "ordem" do espaço urbano, a nova forma de exclusão que se deu a partir da implantação das casas de internamento tinha como alvo os indivíduos que fugiam ou desobedeciam a ordem social imposta. Não eram espaços destinados ao tratamento médico, tampouco visavam à cura dos internos. A segregação e o isolamento proporcionados pela grande internação representavam interesses políticos, sociais, econômicos e morais, relacionados à manutenção do poder estatal. Segundo Desviat,

- enclausuramento em asilos de mendigos, desempregados e pessoas sem teto foi uma das respostas do século XVII à desorganização social e à crise econômica então provocadas na Europa pelas mudanças estabelecidas nos modos de produção. Um enclausuramento, na intenção absolutista de ocultar a miséria, cuja magnitude é atestada pelo número das pessoas hospitalizadas: oito mil na Salpetrière, uma das instituições que compunham o Hospital Geral de

Paris (Desviat, 1999, p. 15).

A pobreza representava, portanto, um obstáculo ao crescimento e desenvolvimento do da sociedade, ao contrário do que acontecia no período da ldade Média. Com a diminuição da influência oficial da religião no Estado, o louco e o marginal passam a ser excluídos da sociedade produtiva. Nesse momento, os aspectos morais são considerados - e não os religiosos, como outrora -, o que faz com que os indivíduos passem a ser encarados como perturbadores da ordem social (Foucault, 1972).

Embora a laicização caracterizasse $\bigcirc$ Estado Moderno, a lgreja não permanecia distante do processo de internação e enclausuramento da pobreza e da loucura. A lgreja dividiu a miséria em dois segmentos: a pobreza submissa e a insubmissa. A primeira refere-se aos indivíduos satisfeitos com sua condição e aceitavam o internamento; na segunda, são considerados os "inimigos da boa ordem", que recusam o que lhes é imposto, por conta disso, tal como os primeiros, devem ser privados de liberdade. Dessa forma, percebe-se que o enclausuramento é utilizado tanto como forma de "manutenção da ordem" quanto estratégia de punição: se o louco aparecia de modo familiar na paisagem

humana da Idade Média, era como que vindo de um outro mundo. Agora, ele vai destacar-se sobre um fundo formado por um problema de "polícia", referente à ordem dos indivíduos na cidade. Outrora ele era acolhido porque vinha de outro lugar; agora, será excluído porque vem daqui mesmo, e porque seu lugar é entre os pobres, os miseráveis, os vagabundos.

A hospitalidade que o acolhe se tornará, num novo equívoco, a medida de saneamento que o põe fora do caminho. De fato, ele continua a vagar, porém não mais no caminho de uma estranha peregrinação: ele perturba a ordem do espaço social. Despojada dos direitos da miséria e de sua glória, a loucura, com a pobreza e a ociosidade, doravante surge, de modo seco, na dialética imanente dos Estados

(Foucault, 1972, p. 63).

De acordo com Foucault (1972), a mendicância e a ociosidade eram também condenadas pelo poder do Estado. Nesse caso, o desempregado, além de sofrer coação física, era também privado de liberdade, e assim se estabelece uma nova forma de ordenamento. Criam-se novas estratégias para o silenciamento dos sujeitos através de um sistema de obrigações: o direito à alimentação deve ser garantido, mas o sujeito deve aceitar a coação física e moral do internamento.

Por um lado, o desemprego gerava um mal-estar socioeconômico, aumentando a criminalidade e a mendicância; por outro, em tempos de pleno emprego, o internamento garantia uma reserva de mão-de-obra barata, visto que boa parte da população internada, ao ser liberta, aceitaria trabalhar por uma remuneração menor. Dentro da sociedade mercantilista, pautada na lógica da produção e do consumo, o destino do pobre, do louco e do desempregado era o internamento. Apenas a população economicamente ativa era "acolhida" no âmbito social. Em períodos de crise econômica, essa era a maneira adotada pelo Estado para manter o funcionamento da sociedade, que conservava altos índices de desemprego e evitava as revoltas pela geração de mão-de-obra barata (Desviat, 1999; Machado, 2009). 
Nessa nova configuração, destaca-se uma distinção em relação à forma anterior de asilamento, pois "o leprosário tinha um sentido apenas médico; muitas outras funções representaram seu papel nesse gesto de banimento que abria espaços malditos. $O$ gesto que aprisiona não é mais simples: também ele tem significações políticas, sociais, religiosas, econômicas, morais" (Foucault, 1972, p. 61). Esse caráter múltiplo da significação dos internamentos fica evidente quando Foucault (1972) ○ relaciona com o momento socioeconômico em questão: os hospitais psiquiátricos eram instalados nas cidades de fundação das indústrias emergentes no início da revolução industrial.

Essa relação nos leva a refletir sobre a fundação da ciência médica e sua relação com a força de trabalho. A medicina moderna é considerada por Foucault (1979) uma medicina social, por trazer em si uma tecnologia voltada para a atenção ao corpo social e ter a atenção individual apenas um eixo de atuação, não um foco. Um dado importante da construção dessa medicina diz respeito à constituição econômica a qual ela está vinculada: o capitalismo. Nesse sistema, a exploração da força de trabalho (e a consequente concepção do trabalho humano como mercadoria), é responsável pela concepção do corpo enquanto força de produção que necessita de atenção: para que a roda da economia não se veja impedida de prosseguir em decorrência de um trabalhador adoentado, por exemplo, é necessário que todos estejam saudáveis e aptos para o trabalho. Daí que o corpo aparece como realidade biopolítica, ou seja, uma instância que diz respeito ao Estado, e a medicina como estratégia biopolítica: cabe a ela a execução dessa prescrição do Estado sobre o sujeito moderno. É na medicina de cunho social que o sistema capitalista encontra a saúde como mais uma forma de controle da participação social dos sujeitos por meio da relação com o corpo: - desenvolvimento das disciplinas e das regulações da população demonstram o poder político na gerência da vida (Foucault, 1979).

No período da mercantilização, o hospital geral aparecia como "uma estrutura semijurídica, uma espécie de entidade administrativa que, ao lado dos poderes já constituídos, e além dos tribunais, decide, julga e executa" (Foucault, 1972, p. 50). Ou seja, o internamento consistia em uma avaliação moral. A exclusão se dava em nome da ordem social e características como a mendicância e a ociosidade eram passíveis de internamento. $O$ indivíduo asilado, portanto, era o sujeito não-produtivo no sistema mercantil:

a internação é uma criação institucional própria ao século XVII. Ela assumiu, desde o início, uma amplitude que não lhe permite uma comparação com a prisão tal como esta era praticada na ldade Média. Como medida econômica e precaução social, ela tem valor de invenção. Mas na história do desatino, ela designa

um evento decisivo: o momento em que a loucura

é percebida no horizonte social da pobreza, da incapacidade para o trabalho, da impossibilidade de integrar-se no grupo; o momento em que começa a inserir-se no texto dos problemas da cidade. As novas significações atribuídas à pobreza, a importância dada à obrigação do trabalho e todos os valores éticos a ele ligados determinam a experiência que se faz da loucura e modificam-lhe o sentido (Foucault, 1972, p. 78).

Desse cenário percebemos ainda a conservação das bases de um asilamento total que, mesmo no século $X X I$, ainda não foi superado. E ainda nos deparamos com os hospitais psiquiátricos, que expõem seu caráter mais higienizador do que terapêutico, de constituição totalizante, não escondendo os pilares do mundo correcional, como o Hospital Especializado Lopes Rodrigues (HELR). Embora o "manicômio da princesa" (Barros, 2016) tenha modificado seu nome e determinadas práticas, conserva ainda, em muitos aspectos, os estigmas da loucura dentro de seus muros.

\section{Totalização institucional}

Fundado em 1962, o Hospital Especializado Lopes Rodrigues (HELR) tinha como objetivo o processo de reabilitação do portador de transtorno mental, em um projeto de modernização da sociedade feirense aplicado concomitantemente à apresentação da medicina social como parceira do projeto de manutenção da ordem urbana (Barros, 2016). Originado em um modelo de colônia agrícola importado da Europa, o espaço serviu como escape da superlotação do Hospital Especializado Juliano Moreira, localizado em Salvador e ainda em atividade. Atualmente, a instituição passa por um processo de desospitalização que visa à revisão dos métodos terapêuticos até então utilizados e busca uma reinser- 
ção social do paciente psiquiátrico, vivendo impasses e polêmicas em relação a sua desativação total.

Embora todas as instituições tendam minimamente ao fechamento, em decorrência da conquista do tempo e do interesse de seus participantes, na instituição de caráter total as barreiras são intensificadas, pois impostas à relação social com o mundo externo e proibição de saída, como é o caso do hospital psiquiátrico, segundo Erving Goffman (1974). A instituição total pode ser definida enquanto "local de residência e trabalho onde um grande número de indivíduos com situação semelhantes, separados da sociedade mais ampla por considerável período de tempo, levam uma vida fechada e formalmente administrada" (p. 11). Além disso:

uma disposição básica da sociedade moderna é que - indivíduo tende a dormir, brincar e trabalhar em diferentes lugares, com diferentes coparticipantes, sob diferentes autoridades e sem um plano racional geral.

O aspecto central das instituições totais pode ser descrito com a ruptura das barreiras que comumente separam essas três esferas da vida. Em primeiro lugar, todos os aspectos da vida são realizados no mesmo local e sob uma única autoridade. Em segundo lugar, cada fase da atividade diária do paciente é realizada

na companhia imediata de um grupo relativamente

grande de outras pessoas, todas elas tratadas da mesma forma e obrigadas a fazer as mesmas coisas e conjunto. Em terceiro lugar, todas as atividades diárias são rigorosamente estabelecidas em horários, pois uma atividade leva, em tempo predeterminado, à seguinte,

e toda a sequência de atividades é imposta de cima

por um sistema de regras formais explícitas e um grupo de funcionários. Finalmente, as várias atividades obrigatórias são reunidas num plano racional único, supostamente planejado para atender aos objetivos oficiais da instituição (Goffman, 1974, p. 17).

Todas estas características contemplam a realidade vivida por aqueles que chegam e que já estão no HELR, totalizados pela loucura. O hospital psiquiátrico configura-se enquanto uma instituição total voltada para o tratamento de pessoas consideradas incapazes cuja ameaça à sociedade se dá de forma não intencional. Nesse espaço, as necessidades humanas são regidas por uma organização burocrática. A individualidade é experimentalmente modificada; 0 comportamento, sistematicamente padronizado; 0 indivíduo, pau- latinamente mortificado. Em decorrência disso, "a fronteira que o indivíduo estabelece entre seu ser e o ambiente é invadida e as encarnações do eu são profanadas" (Goffman, 1974, p. 31). A perda sistemática de direitos conduz à morte civil. A negação da intimidade, à morte subjetiva.

Essas características demarcam o que Goffman (1974) denomina de "carreira moral do doente mental". Transformado de indivíduo em paciente, o doente mental frequentemente expressa um sentimento de injustiça e de traição pela instituição na qual está inserido, isso porque a exposição frequente às experiências de degradação e humilhação dentro do hospital psiquiátrico acabam por institucionalizar a tendência à homogeneização das condutas. As relações de servidão, que são traço das sociedades ocidentais, acabam por refletir diretamente nos problemas encontrados na hospitalização. Escarnecidos de quaisquer traços humanos e dignidade, os indivíduos encontram-se inevitavelmente marcados pela institucionalização e pela alienação da hierarquização no hospital psiquiátrico:

nas instituições totais existe uma divisão básica entre um grande grupo controlado, que podemos denominar

- grupo dos internados, e uma pequena equipe de supervisão. Geralmente, os internados vivem na instituição e têm contato restrito com o mundo existente fora de suas paredes: a equipe dirigente muitas vezes trabalha num sistema de oito horas por dia e está integrada no mundo externo. Cada agrupamento tende a conceber o outro através de estereótipos limitados e hostis - a equipe dirigente muitas vezes vê os internados como amargos, reservados e não merecedores de confiança; os internados muitas vezes veem os dirigentes como condescendentes, arbitrários e mesquinhos. Os participantes da equipe dirigente tendem a sentir-se superiores e corretos; os internados tendem, pelo menos sob alguns aspectos, a sentir-se inferiores, fracos, censuráveis e culpados

(Goffman, 1974, p. 19).

A hierarquização hospitalar demarca de forma bastante rígida a execução do modelo biomédico de psiquiatria, que opta por uma universalidade do tratamento fundamentada na prática do exame. Essa conjuntura, por sua vez, impacta diretamente na construção da subjetividade daqueles que se encontram institucionalizados nos ainda existentes hospitais psiquiátricos: tal como destacado por Goffman 
(1974) é possível observar tanto na instituição total quanto nos serviços substitutivos, que acabam por reproduzir esta lógica, uma hierarquização e estratificação dos papéis sociais, nos quais os profissionais se identificam com a detenção do saber-poder e os pacientes se submetem aos regimes impostos.

Segundo Goffman (1974), os impactos diretos da carreira moral do doente mental em todos os aspectos de sua vida acabam por influenciar diretamente em sua capacidade de julgar a si mesmo e aos outros. A autoimagem do sujeito institucionalizado é reificada e fundamentada pelos estigmas da sua associação com a doença, assim como toda a sua relação com o mundo extra-hospital - quando este é passível de acesso. Embora condenadas pelo sistema de saúde mental, algumas instituições totais ainda protagonizam o cuidado da loucura, como é o caso de Feira de Santana, na qual o hospital psiquiátrico figura-se enquanto instituição-referência na atenção à saúde mental, enfrentando entraves diversos para sua desativação.

De uma forma geral, o trabalho de Goffman nos faz atentar para a necessidade de desinstitucionalização e para a noção de que a "instituição nunca é proteção; favorece mecanismos de violência, controle, perda de autonomia" (Amarante, 2014, p. 15). Nas palavras do autor: "é errônea a crença de que a hospitalização visa ao tratamento de um paciente, sendo o mais comum o fato de que ela necessariamente prejudique suas oportunidades de vida" (Goffman, 1974, p. 293).

Dentro da totalização representada no cenário do HELR, a porta de entrada é a emergência. $O$ atendimento emergencial tem como prazo máximo setenta e duas horas, que objetivam a observação e tentativa de compensação do paciente. Caso não seja possível, a internação faz-se necessária. A emergência consta com leitos femininos e masculinos, além de um espaço reservado para crianças. Aqui, devemos destacar o relato de uma funcionária do espaço: embora a instituição receba crianças, há uma dificuldade em lidar com tal público, principalmente, pela ausência de um serviço de rede com o Hospital da Criança (HEC) da cidade. Os principais diagnósticos realizados são de transtorno bipolar, esquizofrenia e uso de substâncias psicoativas. $O$ espaço da emergência também conta com atendimentos em cardiologia e odontologia, por exemplo.

Nesse cenário, percebemos que $\circ$ processo que se opera é de desospitalização, não de desinstitucionalização. A desinstitucionalização representa, sobretudo, a ruptura com o paradigma da razão que compreende a loucura enquanto sinônimo de doença ou patologia orgânica. Para além da modificação na estrutura física do manicômio, com a redução de leitos e do tempo de internação, desinstitucionalizar aponta para uma reestruturação dos saberes e práticas vigentes, isso significa romper com o modelo asilar de controle e exclusão social (Rotelli, 2001). Como consequência, a assistência à saúde mental passa a ocupar-se do sujeito e de sua subjetividade, deixando de focar numa hipotética doença orgânica e passando a abordar a complexa trama das relações sociosimbólicas. De modo geral, este se configura como um movimento mais amplo e abrangente que a desospitalização, afinal, a criação de serviços substitutivos para os hospitais psiquiátricos, como propõe a desospitalização, pode gerar uma nova forma de asilamento e cronicidade, uma vez que não prevê a superação do modelo manicomial como o processo de desinstitucionalização (Delgado, 2007). Em decorrência do processo de desospitalização, o Hospital Lopes Rodrigues funciona com capacidade reduzida, embora já tenha chegado a contar com mais de oitocentos pacientes, os relatos são variados. Segundo Barros (2016, p. 47):

os dados investigados no livro colaboraram com certas afirmações: 1 - o número de entrada de pacientes no hospital foi crescendo gradativamente durante a década de sessenta. Isso pode ser atrelado ao próprio desenrolar quantitativo da instituição. Ao mesmo tempo em que surgiam demandas sociais de internamentos na instituição, aumentava-se seu aparato estrutural para dar conta das emergencialidades suscitadas. Tal prerrogativa pode ser constatada no dilatamento da quantidade de pacientes. Em 1962

a população residente era de 31 pacientes, esse número chegou a ser de mais, em meados da década de 1980, de 800 conforme nos aponta a Secretaria de Saúde da Bahia (SESAB). Com o passar dos anos sua capacidade estrutural foi aumentando, com isso a entrada de pacientes acompanhava quantitativamente. 2 - os anos de 1968 e 1969 foram os que obtiveram maior número de entradas (respectivamente 77 e 
72 entradas), concomitantemente nesse período a cidade de Feira de Santana intensificava o seu projeto modernizador, a chegada de um polo industrial foi uma das principais marcas desse projeto no período. 3 - as principais patologias ligadas ao internamento eram: esquizofrenia, alcoolismo crônico, psicose alcoólica e em muitos casos a causa não era definida.

Atualmente, a instituição tem como número máximo de pacientes por pavilhão de internamento dezesseis pessoas. Considerando a existência de dois espaços (feminino e masculino), há tolerância máxima de 32 pacientes nas dependências do hospital destinadas a estes internos. Outros dois pavilhões ainda contam com internos: a Unidade Psicogeriátrica (UPG) e a Unidade de Longa Permanência (ULP).

A redução de recursos humanos impede a execução de tarefas mais efetivas que não abandonem os pacientes aos dias de ócio e, assim à mortificação do eu (Goffman, 1974). A unidade psicogeriátrica (UPG) é a seção que conta com mais funcionários, em decorrência das necessidades especiais dos pacientes que ali se encontram. Além daqueles que já tem mais de sessenta anos, a UPG abriga também pacientes mais novos que apresentem alguma vulnerabilidade física. A Unidade de Longa Permanência (UPL) abriga os pacientes que estão no hospital desde antes da Lei 10.216 (Brasil, 2001). Nessa seção, encontram-se os pacientes cronificados e que não necessariamente possuíam um diagnóstico de transtorno mental na ocasião de seu internamento. Ali, encontram-se aqueles que foram vitimados pelo processo de segregação que contou com o manicômio como dispositivo de exclusão. Como reflexo do cenário atual do hospital, há dois lares abrigados, nos quais é realizado o processo de transição para as residências terapêuticas através do desenvolvimento da autonomia do paciente, projeto pioneiro instalado pelos profissionais da instituição. Nesse espaço, atualmente há onze moradores. Em Feira de Santana, contamos com onze Residências Terapêuticas (RT). Outras cidades do estado também receberam os pacientes do Lopes Rodrigues, como Euclides da Cunha e Itapetinga, por exemplo.

De modo geral, a partir do contato com os profissionais atuantes nesses espaços, pudemos perceber um discurso de senso comum e cunho religioso extre- mamente arraigado, revelando as fragilidades da oferta deste serviço e das condições de formação oferecidas no país, pouco atualizadas ou voltadas a uma perspectiva crítica da realidade. Os profissionais se tornam, então, reprodutores de uma forma de opressão, que agora é simbólica, destacando a separação radical entre os detentores e os não detentores de poder. A violência das correntes e camisas de força adquire nova roupagem: uma violência técnica e sistemática continua instituída neste espaço por meio da coisificação dos indivíduos e da redução ao imediatismo do racionalismo médico (Cooper, 1967; Basaglia, 1985). Além disso, a ausência generalizada de terapêutica no espaço asilar fica evidente, remetendo aos moldes descritos dos primeiros internamentos. Assim sendo, percebemos a manutenção da mentalidade manicomial no trato com os pacientes, mesmo com o fim da arquitetura da exclusão.

\section{A necessidade de desinstitucionalização}

Devido à mudança do objeto de estudo da psiquiatria, da doença mental já instalada para a promoção de saúde mental, instaurou-se uma crise teórica e prática neste campo do saber que culminou na crítica do modelo asilar de psiquiatria e na defesa de uma extensão de sua ação ao espaço público (Amarante, 1995).

Desde o seu surgimento, no final do século XVIII, a psiquiatria se propunha, como disciplina médica, à terapêutica dos distúrbios mentais, sendo que seu campo de cientificidade abrangia o estudo destas doenças e das indicações de sua instrumentalidade curativa. Entretanto, na modernidade, o seu objeto teórico pretende-se outro: a psiquiatria pretende-se um saber sobre a Saúde Mental, sobre as suas condições de possibilidade e sobre as formas de instaurá-la originariamente nos indivíduos (Birman; Costa, 1994, p. 43).

A partir da década de 1950, no contexto de pós-guerra, fortemente influenciado pela contracultura, foram instaurados modelos alternativos de psiquiatria, dentre os quais as comunidades terapêuticas, a psicoterapia institucional, a psiquiatria de setor e a psiquiatria preventiva. Nas décadas seguintes, destacamos os movimentos da antipsiquiatria e da psiquiatria democrática italiana (PDI). 
As comunidades terapêuticas surgiram na Inglaterra com o objetivo de transformar a dinâmica institucional asilar por meio da adoção de medidas administrativas, participativas e coletivas. Além disso, havia uma ampla utilização da terapia ocupacional como tentativa de recuperação da mão de obra que fora invalidada pela guerra. A psicoterapia institucional tem na figura de Tosquelles e na abertura dos portões da instituição seu grande marco, entretanto, limitava-se justamente pela impossibilidade de superar a necessidade da instituição (Amarante, 1995). A psicoterapia de setor, por outro lado, visava à contestação do modelo asilar por meio do tratamento do paciente em seu meio social, tendo o internamento como apenas uma das etapas do processo. Esse modelo, também instaurado na França, mostrou-se oneroso e perigoso frente a ideologia dominante. Nos Estados Unidos, a psiquiatria preventiva atuou com intervenção nas causas das doenças mentais e na promoção de saúde mental. Nesse modelo, o conceito de crise elaborado por Gerald Caplan foi central (Tenório, 2002).

A antipsiquiatria foi um movimento iniciado na década de 1960 pelo psiquiatra sul-africano David Cooper em parceria com o também psiquiatra Robert Laing como discordância dos métodos de estudo e ação da psiquiatria e psicologia tradicionais, fortemente impregnados pelas tendências e práticas das ciências naturais (Duarte Jr., 1983). Nessa concepção, a visão fragmentada da mente humana é criticada e a loucura analisada por um viés político, baseado nas relações de poder que permeiam a sociedade e na crítica à alienação social. $O$ movimento antipsiquiátrico defendeu que o contato com sujeitos deve partir de uma fundamentação nas ciências humanas, por lidar com o homem em relação, não isolado ou destituído da influência do contexto socioeconômico. Como movimento de controle social dos excluídos, a psiquiatria estaria a serviço de uma condição sociocultural doente que acaba por adoecer os sujeitos:

a construção social de patologias se faz a partir do uso do poder, em contexto em que dita as normas quem sabe mais, só restando aos destituídos do conhecimento,

ao excluídos do sistema, a alternativa de aceitar sua condição de doentes. As instituições, como portadoras de conhecimentos e saberes fortalecidos por seus discursos, legitimam suas práticas. Ao ser rotulado de louco, por exemplo, o indivíduo vai incorporando aos poucos essa ideia e passando a se comportar como se tal fosse. Basta manter um homem psicologicamente saudável por algum tempo em um manicômio para que em breve ele se dê como louco. A psiquiatria tradicional se torna violenta ao criar patologias e impedir o doente de se expressar. Reserva-se o direito de dizer a verdade sobre o indivíduo, impedindo que ele se manifeste e retirando-lhe o direito de defender-

se, pois tudo o que disser será interpretado como sintomas de sua doença (Oliveira, 2011 , p. 153).

Durante a década de 1970, surge neste cenário a figura do psiquiatra italiano Franco Basaglia, que propõe a desinstitucionalização dos hospitais psiquiátricos a partir da desconstrução do modelo manicomial asilar e da mentalidade hospitalocêntrica. Por meio do movimento de Psiquiatria Democrática Italiana (PDI), O trabalho de Basaglia consistiu em um projeto político de recuperação da cidadania dos pacientes (Amarante, 1995). O trabalho de Basaglia consistia na discussão das formas de violência e perpetração do poder propiciadas pelo movimento de institucionalização. Em sua concepção, mais importante do que a instituição é a compreensão das formas de condenação dos desvios em uma sociedade do capital:

isto não significa que não exista o problema da doença mental e da delinquência, ou seja, que não exista o diferente como fenômeno humano e que a transformação de base social seja suficiente para suprimi-lo. O problema está justamente na incorporação deste conceito, isto é, na necessidade de fazer desaparecer o diferente como se a vida não $\circ$ contivesse, ou eliminar, assim, tudo aquilo que possa pôr em dúvida a falsa coerência desta face lisa e polida, na qual tudo andaria bem se não fossem as "ovelhas negras" (Basaglia, 1986, s/p).

É esse pensamento que acaba por fundamentar teoricamente a proposta de reformulação do pensamento manicomial em nosso país, que visa à superação da violência asilar. No Brasil, a reforma psiquiátrica, ainda em curso, ocorre a partir da década de 1980, juntamente com a redemocratização do país e a instauração do Sistema Único de Saúde (SUS) em 1988. O processo decorre de uma crise nas instâncias regedoras da saúde mental no país e é fortalecido pela criação do Movimento dos Trabalhadores em Saúde Mental (MTSM) e 
pela proposta de lei 10.2016 , regulamentando os direitos dos portadores de transtorno mental e a extinção progressiva da estrutura manicomial (Brasil, 2001). Com o fomento da discussão sobre a violência nos cuidados psiquiátricos e questionamento de seu sucesso a partir de um discurso humanitário, esses elementos compõem a legalização da transição dos métodos asilares para uma psiquiatria descentrada:

a reforma psiquiátrica é a tentativa de dar ao problema da loucura uma outra resposta social, não asilar: evitar a internação como destino e reduzi-la a um recurso eventualmente necessário, agenciar o problema social da loucura de modo a permitir ao louco manter-se, como se diz, na sociedade (Tenório, 2002, p. 55).

Dessa forma, a reforma psiquiátrica brasileira é caracterizada pela descentralização do serviço psiquiátrico com a implantação dos primeiros Centros e Núcleos de Atenção Psicossocial (CAPS e NAPS, respectivamente) a partir de 1987, iniciando o movimento popularmente conhecido como Luta Antimanicomial. Por meio de diferentes intervenções, estes serviços visavam promover a diminuição da quantidade de leitos e hospitais acompanhada da criação de alternativas de assistência, além de uma ação integrada e cidadã no cuidado de pessoas com sofrimento psíquico. Em geral, os CAPS têm como carro-chefe atividades de oficinas terapêuticas que se apresentam como alternativa ao tratamento medicamentoso. Nas palavras de Bezerra Jr. (2007, p. 247):

mais do que buscar a aceitação de uma nova política assistencial, o desafio nesse campo é produzir uma nova sensibilidade cultural para com o tema da loucura e do sofrimento psíquico. Trata-se de promover uma desconstrução social dos estigmas e estereótipos vinculados à loucura e à figura do doente mental, substituindo-os por um olhar solidário e compreensivo sobre a diversidade e os descaminhos que a experiência subjetiva pode apresentar, olhar

fundado numa atitude de respeito, tolerância e responsabilidade com aqueles que se encontram com sua normatividade psíquica restringida.

OS atendimentos em CAPS devem estar orientados para a promoção de autonomia dos sujeitos em relação aos seus processos de saúde-doença, de modo que este possa tornar-se protagonista no processo de construção de novas possibilidades de vida comunitária e familiar, novas formas de relações afetivas e novos modos de transitar em espaços sociais. $O$ trabalho do profissional nesse cenário, fundamentado teoricamente por uma perspectiva antropológica do sujeito e das relações, deve estar menos direcionado para a cura de uma doença ou de um sintoma e mais para a produção de "subjetividades inconformadas", no sentido de sujeitos em recusa da reprodução apática e homogênea imposta pela sociedade moderna, por seus modos de controle, pela organização de suas relações de trabalho e pelos processos de sustentação do modo de produção atual (Conselho Federal de Psicologia, 2013).

Embora a proposta dos movimentos de contestação em meados do século XX e também da reforma psiquiátrica brasileira seja a de colocar a doença entre parênteses e refletir sobre a experiência do sujeito, esse projeto parece não se efetivar muito bem no cotidiano. A proposta é de desinstitucionalização da saúde mental. $O$ que observamos, entretanto, é uma mera desospitalização, que acaba por instaurar novas formas de institucionalização dos sujeitos: "há uma confusão sobre a superação do modelo assistencial hospitalar asilar manicomial, que está em processo razoável, embora hoje haja novas formas de institucionalização, como as comunidades terapêuticas e as instituições religiosas" (Amarante, 2014, p. 17).

Nos Centros de Atenção Psicossocial visitados na cidade de Feira de Santana, o modelo vigente ainda é o orientado em uma perspectiva manicomial, sem articulação em rede e efetivação no território. Segundo a coordenadora da Rede de Saúde Mental (RAPS) de Feira de Santana, Robervânia Cunha (2018), entraves políticos - como as diferentes gestões dos CAPS (municipal) e do HELR (estadual) -, insuficiência de verba, rotatividade e déficits formativos dos profissionais, bem como uma mentalidade arraigadamente preconceituosa da sociedade em relação ao transtorno mental são fatores que provocam a desarticulação e desassistência da RAPS, impedindo a concretização de um processo de desinstitucionalização efetivo. A ausência de determinados recursos, por exemplo, impede a realização de atividades alternativas e reconduz a tera- 
pia ao tratamento medicamentoso. A desarticulação da rede (mesmo a nível municipal) faz com que mais de $50 \%$ dos matriculados em CAPS sejam de transtorno mental leve, quando sua totalidade deveria ser de transtorno severo, grave e persistente, assim como a presença de questões decorrentes de vulnerabilidades sociais surgem no serviço, aumentando uma demanda que não tem condições de ser cumprida em sua inteireza.

Nesse sentido, é importante refletir sobre a totalização institucional (Goffman, 1974) para além da estrutura física, considerando-se que muitos dos aparatos técnico-racionais amparados pela reforma psiquiátrica recaem em novas formas de institucionalização. Nesse cenário, também encontramos sujeitos enredados na dependência de uma teia do tratamento farmacológico. A quebra das paredes dos manicômios, de certa forma, ofereceu à psiquiatria todo um campo de intervenção, uma "psicocracia" ou imperialismo psiquiátrico nos termos de Castel (1987), conduzindo a sociedade ao processo de medicalização da vida cotidiana.

\section{Da institucionalização à medicalização}

Segundo a tradição foucaultiana, a medicalização pode ser definida enquanto uma expansão da medicina para além do seu campo de atuação, tomando como médico aquilo que é político e social, por exemplo. Esse processo faz com que "as pessoas sintam que seus problemas são problemas de saúde e não próprios da vida humana" (Amarante, 2007, p. 95). O processo intenso de aplicação de fármacos também tende a ser considerado como uma forma medicalização, embora possa ser chamado de "farmacologização" para evitar uma ambiguidade em relação à compreensão do processo mais amplo. De uma forma geral, temos que, para além da recorrência indiscriminada ao uso de fármacos, a medicalização diz respeito a uma racionalidade tecnicista que reduz questões políticas, econômicas e sociais ao âmbito do individual, biológico, desconsiderando a complexidade da vida humana e apresentando-se como ideologia. A patologização, a psicologização, a psiquiatrização e a criminalização da pobreza e das diferenças encontram espaço fértil neste terreno.
Um aspecto importante da relação entre a medicalização e a saúde mental é o que Camargo Jr. (2007) denomina de complexo médico industrial (CMI). O conglomerado formado pela indústria farmacêutica e de equipamentos médicos, empresas de educação e formação de profissionais de saúde, mercado de seguradoras e publicações na área, dentre outros sistemas que atuam nesse sentido, compõe um arsenal de atuação da saúde sobre a vida. O discurso de promoção e aquisição de saúde toma a vida social do sujeito como um todo, sendo generalizado de forma exponencial principalmente pela atuação da mídia nesse processo medicalizador. Aqui, o médico é a figura de certificação de um mercado em expansão crescente, operando na disseminação do discurso científico como argumento cotidiano para as mais variadas situações. Essa centralidade da figura médica pode ser observada tanto no HELR quanto nos CAPS feirenses: embora - modelo empregado seja o de descentralização, a maior função dos espaços de saúde mental na cidade é a de oferta de consultas psiquiátricas e distribuição de fármacos, dando a entrever a manutenção de uma perspectiva institucionalizadora medicalizante e uma dessemelhança entre o apregoado pela legislação vigente (Brasil, 2001) e a prática profissional.

Nesse contexto, também é possível observar uma reificação do conceito de doença, que perde espaço nas discussões, pois o foco da díade saúde-doença encontra-se apenas no primeiro ponto (Camargo Jr., 2007). A doença não é tomada como um artefato teórico e heurístico passível de estudo e compreensão, mas como uma coisa. O sofrimento decorrente da doença é coisificado/naturalizado e - sujeito adoecido (exposto às maravilhas da saúde presentes na sociedade contemporânea) é culpabilizado, afinal, em um universo de possibilidades em que o imaginário saudável impera, o adoecimento é condenável. $O$ que ocorre é um ciclo vicioso, no qual a medicalização e a biologização da vida voltam a amparar o discurso científico de saúde.

Esse processo certamente encontra suas raízes na falsa desinstitucionalização empregada na saúde mental, a qual tenta, segundo Rotelli (1988, p. 91), "mumificar o objeto da psiquiatria, deslocando apenas as formas e os modos de gestão, mais que 
qualquer outra coisa, os lugares, o look". O mesmo saber-poder regedor do processo de institucionalização encontra-se imbricado na produção de medicalização da sociedade, fortalecendo o domínio da soberania sobre os corpos. Nas palavras de Foucault (1979, p. 47): "o corpo é uma realidade biopolítica, a medicina é uma estratégia biopolítica". Política dos corpos que deixa suas marcas na impossibilidade de realizar uma desinstitucionalização eficaz, reduzindo os processos de reforma a meras desospitalizações:

o trabalho se concentrou na desospitalização. Quando falamos em desmedicalização, não estamos falando em diminuição do medicamento, e sim na diminuição do papel da medicina. Queremos diminuir a apropriação que a medicina faz da vida cotidiana, o discurso médico sobre a vida. Isso não conseguimos. Um desafio hoje da reforma psiquiátrica é a formulação discursiva muito médica, por exemplo, as pessoas são contra o manicômio, mas não abrem mão do conceito de depressão tal qual utilizado pela indústria farmacêutica

(Amarante, 2014 , p. 17).

\section{Considerações finais}

Frente à realidade aqui apresentada, é imprescindível questionar o papel do psicólogo - tanto no que foi realizado historicamente como o que pode vir a ser uma psicologia socialmente comprometida com a emancipação humana e a mudança social. É importante refletirmos sobre o estatuto da psicologia enquanto crítica e, também, objeto da barbárie que denuncia (Macêdo; Santos, 2018). Retomando o pensamento de Basaglia, não podemos deixar de questionar sobre o papel da psicologia nos movimentos de institucionalização e medicalização registrados. Não é possível fechar os olhos para a práticas que funcionam como estratégias de dominação e ratificam o cenário aqui descrito:

frente a esta realidade, qual é a tarefa do psiquiatra, do psicólogo, do criminólogo que atuam no âmbito institucional? Criar uma alternativa para a intervenção técnica deveria significar chegar a traduzir nossa ação na prestação de um serviço que sirva, justamente enquanto tal, ao assistido e ao mesmo tempo a sua tomada de consciência da utilização, contra ele mesmo, que geralmente se dá a este serviço.
Significa, portanto, tomar consciência de que cada intervenção técnica tem em si mesma uma efetiva finalidade política: a de ser um dos instrumentos dos quais se serve a classe dominante para perpetuar sua dominação. Mas além dos privilégios que gozamos enquanto técnicos burgueses sujeitos da dominação implícita em nosso "rol" de poder, podemos ainda tentar ser agentes de transformação mediante a

localização das necessidades, na prática real, e o desmascaramento dos processos que convertem as ditas necessidades (também nos olhos de quem as expressa) em algo distinto daquilo que são (Basaglia, 1986, s/p).

A resposta para essa reflexão pode ser encontrada no próprio Basaglia, em escrito anterior a este, no qual denuncia as violências do contexto institucional, da qual o profissional também faz parte:

não há outra solução senão refutar o ato terapêutico cujo único objetivo é atenuar as reações dos excluídos em relação ao excludente. Mas para tanto é necessário que nós próprios, prepostos do poder e da violência, tomemos consciência de que também somos excluídos pelo próprio fato de havermos sido objetivados no papel de excludentes (Basaglia, 1985, p. 103).

Essa perspectiva ratifica a necessidade de centralização do trabalho do psicólogo no sujeito, na sociedade, e não na doença, principalmente no que diz respeito à produção social da doença. Assim como de articulação do trabalho em rede e nos territórios, potencializando a possibilidade de modificação da concepção patologizadora e medicalizador da diferença, solo no qual se fundamentam muitas das práticas do campo psi, inclusive na cidade de Feira de Santana. Além disso, evidencia a necessidade de revisão da prática da psicologia coadunando com a questão dos direitos humanos, o respeito à diferença e o combate à desigualdade social. Através do contato com os serviços de saúde mental percebemos que $\circ$ "cuidado ideal é o que preenche a vida de cada um de sentido: habitação, emprego e o que mais necessitamos para permanecer saudáveis. Com os que estão em tratamento, sugeriu, o importante é ouvi-los sobre o que desejam e o que os ajuda a melhorar" (Dominguez, 2014, p. 13).

Por isso, é necessário romper com as novas formas de institucionalização, sejam elas físicas, mentais 
ou ideológicas, com a individualização que decorre do processo de medicalização no qual estamos inseridos, possibilitando ressignificar nossa atuação no campo da saúde mental e realizar uma articulação eficaz em rede e com os demais profissionais. É necessário repensar a dominação do conhecimento, assim como o papel dos sujeitos em uma sociedade estruturalmente injusta. Para tanto, é necessário ter em mente que "imaginar um futuro diferente para a saúde mental é imaginar uma sociedade diferente" (Dominguez, 2014, p. 12), no qual assumamos a fragilidade da bastilha da razão humana em decorrência da fragmentação da sociedade em que vivemos.

\section{Contribuições dos autores}

Barboza, W. C. S. participou da concepção, delineamento, busca e análise estatística dos dados da pesquisa, interpretação dos resultados, redação do artigo científico. Macêdo, S. A. participou da coleta de dados da pesquisa, interpretação dos dados. Tsukuda, Y. F. participou da concepção, delineamento, análise estatística dos dados da pesquisa, interpretação dos resultados, redação e encaminhamento do artigo científico.

\section{Conflitos de interesses}

Nenhum conflito financeiro, legal ou político envolvendo terceiros (governo, empresas e fundações privadas, etc.) foi declarado para nenhum aspecto do trabalho submetido (incluindo mas não limitandose a subvenções e financiamentos, conselho consultivo, desenho de estudo, preparação de manuscrito, análise estatística, etc).

\section{Referências}

Amarante, P. (1995). Revisitando os paradigmas do saber psiquiátrico. In P. Amarante, Loucos pela vida: a trajetória da reforma psiquiátrica no Brasil (pp. 13-55). Rio de Janeiro: Fiocruz.

Amarante, P. (2007). Saúde mental e atenção psicossocial. Rio de Janeiro: Fiocruz.

Amarante, P. (2014). 'Queremos diminuir a apropriação que a medicina faz da vida cotidiana' [Internet]. Recuperado de http://www6. ensp.fiocruz.br/radis/revista-radis/146/ reportagens $/ \%$ E2\% $\% 0 \% 98$ queremos-diminuirapropriacao-que-medicina-faz-da-vidacotidiana $\%$ E2\%80\%99
Barros, M. O. (2016). O 'manicômio da princesa': reflexões sobre a psiquiatria institucional em Feira de Santana Bahia (Trabalho de Conclusão de Curso). Universidade Federal do Recôncavo Baiano, Cachoeira, BA, Brasil.

Basaglia, F. (1985). A instituição negada: relato de um hospital psiquiátrico. In Basaglia, F., As instituições da violência (pp. 99-134). Rio de Janeiro: Edições Graal.

Basaglia, F. (1986). O homem do pelourinho. São Paulo: Educação e sociedade.

Bezerra Junior, B. (2007). Considerações sobre terapêuticas ambulatoriais em saúde mental. In Silvério A. Tundis, Nilson do Rosário Costa (orgs.), Cidadania e loucura: políticas de saúde mental no Brasil ( 8 a ed., pp. 133169). Petrópolis, RJ: Vozes.

Birman, J., \& Costa, J. F. (1994). Organização de instituições para uma psiquiatria comunitária. In P. Amarante (org.), Psiquiatria social e reforma psiquiátrica (pp. 41 72.). Rio de Janeiro: Fiocruz.

Lei n o 10.216, de 6 de abril de 2001. Dispõe sobre a proteção e os direitos das pessoas portadoras de transtornos mentais e redireciona o modelo assistencial em saúde mental. Recuperado de http://www. planalto.gov.br/cciVil_03/LEIS/LEIS_2001/L10216. htm

Camargo Jr., K. R. (2007). As armadilhas da "concepção positiva de saúde". PHYSIS: Revista de saúde coletiva, 17(1), 63-76. Recuperado de http://www.scielo.br/ pdf/physis/v17n1/v17n1a05.pdf. doi: 10.1590/ S0103-73312007000100005

Castel, R. (1987). A gestão dos riscos: da psiquiatria à psicanálise. Rio de Janeiro: Francisco Alves.

Conselho Federal de Psicologia. (2013). Referências técnicas para atuação da(o) psicóloga(o) no Centro de Atenção Psicossocial. Brasília: Autor. Recuperado de https:// site.cfp.org.br/publicacao/referencias-tecnicas-paraatuacao-de-psicologasos-no-caps-centro-de-atencaopsicossocial/

Cooper, D. (1967). Psiquiatria e antipsiquiatria. São Paulo: Perspectiva.

Delgado, P. G. (2007). Perspectivas da psiquiatria pós-asilar no Brasil (com um apêndice sobre a questão dos cronificados). In S. A. Tundis, \& N. R. Costa (Orgs.), Cidadania e loucura: políticas de saúde mental no Brasil (8 ${ }^{a}$ ed., pp. 171-202). Petrópolis, RJ: Vozes.

Desviat, M. (1999). A reforma psiquiátrica. Rio de Janeiro: Fiocruz.

Dominguez, B. (2014). Novas formas de prisão. Radis: saúde mental, atenção integral supera medicalização da vida, 10-13. 
Duarte Junior, J. F. (1983). A política da loucura: a antipsiquiatria. Campinas: Papirus.

Foucault, M. (1972). História da loucura. São Paulo: Perspectiva.

Foucault, M. (1979). Microfísica do poder (21 a ed.). São Paulo: Paz e Terra.

Goffman, E. (1974). Manicômios, prisões e conventos. São Paulo: Perspectiva.

Macêdo, S. A., \& Santos, T. A. (2018). Afinidades eletivas entre a Teoria Crítica da Sociedade e a Psicologia da Libertação. Revista Ideação, 1 (36), 183-198. Recuperado de http://periodicos.uefs.br/index. $\mathrm{php} / \mathrm{revistaideacao/article/view/3154/2546.} \mathrm{doi:}$ 10.13102/ideac.v1i36.3154

Machado, R. (2009). Foucault, a ciência e o saber ( $4^{a}$ ed.) Rio de Janeiro: Jorge Zahar.

Acorda Cirdade (2018, janeiro 26). Mais de 27 mil pessoas estão cadastradas para atendimento nos Caps em Feira [Internet]. Recuperado de https://www. acordacidade.com.br/noticias/188911/mais-de-27mil-pessoas-estao-cadastradas-para-atendimento-noscaps-em-feira.html?mobile $=$ true

Marconi, M. A., \& Lakatos, E. M. (2006). Metodologia do trabalho científico: procedimentos básicos, pesquisa bibliográfica, projeto, relatório, publicações e trabalhos científicos (6a ed.). São Paulo: Atlas.

Oliveira, W. V. (2011). A fabricação da loucura: contracultura e antipsiquiatria. História, Ciências, Saúde, 18(1), 141-154. Recuperado de http://www. scielo.br/pdf/hcsm/v18n1/09.pdf. doi: 10.1590/ s0104-59702011000100009

Rotelli, F. (1988). A instituição inventada. In: F. Nicácio (Org). Desinstitucionalização (2a ed., pp.89-100). São Paulo: Editora Hucitec.

Silva Filho, J. F. (2007). A medicina, a psiquiatria e a doença mental. In Silvério A. Tundis, Nilson do Rosário Costa (Orgs.), Cidadania e loucura: políticas de saúde mental no Brasil (8a ed., pp. 75-102). Petrópolis, RJ: Vozes.

Tenório, F. (2002). A reforma psiquiátrica brasileira, da década de 1980 aos dias atuais: história e conceito. História, Ciências, Saúde, 9(1), 25-59. Recuperado de http://www.scielo.br/pdf/hcsm/v9n1/a03v9n1.pdf. doi: $10.1590 /$ S0104-59702002000100003 